\title{
A obra de Goethe e o viajante naturalista Humboldt: à prática científica do trabalho de campo
}

\author{
The work of Goethe and traveler naturalista Humboldt: the scientific practice \\ field work
}

\author{
Cleire Lima da Costa Falcão ${ }^{1}$ e José Falcão Sobrinho² \\ ${ }^{1}$ Profa. Dra. do Curso de Geografia da Universidade Estadual Vale do Acaraú/UVA, Sobral, CE, Brasil; \\ cleirefalcao@gmail.com \\ ${ }^{2}$ Prof. Dr. do Curso de Mestrado em Geografia da UVA, Sobral, CE, Brasil; \\ falcao.sobral@gmail.com
}

\begin{abstract}
Resumo
A proposta central desse artigo, eminentemente de natureza teórica, consiste em uma análise do pensamento científico de Johann Wolfgang Von Goethe (1749-1832), o qual, imbuído de uma visão holística, apresenta uma concepção de ciência natural que exige do individuo um desenvolvimento que o capacite a abranger, na visão de realidade, o homem e o mundo, na busca para a compreensão da natureza. A sua concepção de se fazer ciência, justamente com os fatores que justificam determinadas presenças e influências teóricas na contribuição de seus estudos, representa igualmente com a prática científica de alguns de seus contemporâneos tais como viajantes naturalistas o botânico Karl Martius, Darvin e Humbolt, este último destacaremos a sua influência com o método fenomenológico de Goethe.
\end{abstract}

Palavras-Chave: Pensamento Geográfico; Natureza; Método Científico

\begin{abstract}
The central purpose of this article, from mostly theoretical nature, consists of an analysis of scientific thought of Wolfgman Johann von Goethe (1749-1832), who, imbued with a holistic view, presents a conception of natural science that requires from individual the development to enable oneself to cover, in view of reality, the man and the world in the search for understanding of the nature. Its conception of doing science, precisely the factors that justify certain presences and theoretical influences in the contribution of their studies also represent with the scientific practice of some of his contemporaries such as naturalist travelers botanist Karl Martius, Darvin and Humbolt, this last highlight its influence with the phenomenological method of Goethe.
\end{abstract}

Keywords: Geographical Thought; Nature; Scientific Method 


\section{Introdução}

É claramente perceptível à busca da expansão do saber, por diversos autores na História da Ciência, a partir de seu papel, seja como botânico ou naturalistaviajante, cuja atenção era cada vez mais voltada para os funcionamentos internos e os sistemas fisiológicos. As mudanças ocorridas na história da ciência natural nos séculos XVIII e XIX refletem um período tido como o momento de maior especialização e de profissionalização entre os praticantes da História natural.

Para grande parte dos naturalistas do século XIX, a multiplicidade de sensações que envolvem o naturalista em sua viagem poderia ser descrita pela ciência. $\mathrm{O}$ viajante recorria não apenas a produzir ciência in loco, mas ver com os próprios olhos, ouvir e sentir o próprio corpo os fenômenos, registrando as sensações e fenômenos, em consonância com os métodos científicos estabelecidos na época do que serve de exemplo o trabalho de Goethe.

Historizando os primórdios da Geografia, os trabalhos de campo são partes fundamentais do método de trabalho dos geógrafos. A sistematização da Geografia foi embasada principalmente por viajantes naturalistas, que contribuíram com mananciais de informações essenciais para a construção das bases desta ciência. Dentre os estudiosos emergentes desta ciência, temos Alexandre Von Humboldt que obteve o titulo de sistematizador do saber geográfico produzido até então. Foi o primeiro na Geografia a realizar um trabalho de campo sistemático por meio das grandes viagens e dos trabalhos artísticos no qual propunha uma observação minuciosa dos elementos da paisagem.

Neste buscar os primórdios do conhecimento geográfico e os seus influenciadores, explanamos a prática científica de alguns contemporâneos de Goethe e suas concepções acerca de como se fazer ciência, junto aos fatores que justificam determinadas presenças/ influências teóricas na contribuição de seus estudos. Deteremos-nos, especialmente, em algumas das discussões temáticas que aproximam os pensadores Goethe e Humboldt quanto ao modo de se fazer ciência, ao privilegiar o trabalho de campo. Antes, porém, de apresentarmos, é justo e compreensível nos determos em um breve esboço da trajetória do pensamento de Johann Von Wolfgang Goethe, no sentido de esclarecer os traços totalizantes desse pensador/escritor/ cientista, juntamente com seu pensamento científico e literário, nos quais se deixa ao pertencer a um determinado contexto histórico e social. Do conjunto de suas contribuições científicas, temos como a mais importante, a sua visão totalmente fenomenológica, ao procurar entender a natureza e as suas leis internas e não procurar explicações por forças provenientes do exterior. Ele criou um método de compreender a natureza, buscando a essência do fenômeno, como passo inicial, usando a observação.

\section{Johann Wolfgang von Goethe: vida e obra múltiplas em seus interesses culturais e científicos}

Johann Wolfgang von Goethe nasceu em 28 de agosto de 1749 em Frankfurt am Main, sobre o rio Meno, na Alemanha, e faleceu em março de 1832, aos 83 anos, em Weimar. Filho mais velho de um advogado rico, Johan Kaspar Goethe, e de uma aristocrata, Katharine Elizabeth Textor, teve uma infância cercada de bastante conforto e recursos. A primeira educação foi dada por seus pais, e depois continuada por mestres contratados como tutores (STEINER, 1984).

Sua formação universitária foi marcada pela diversidade de conhecimento nas áreas humanas, sociais aplicadas e da natureza, tendo-se iniciada em 1764. Aos 16 anos, foi enviado para ingressar na Universidade de Leipzig, onde estudou Direito, mesmo não tendo especial interesse nesta área. Estudou Belas Artes, Latim, Grego, Francês, Italiano, e fez os cursos de Medicina, Botânica, História, Geologia e Ciências Políticas.

O desenvolvimento do espírito de Goethe fora formado quando ainda muito jovem, desenvolvendo-se por toda a sua vida. Suas ideias estavam prefiguradas no primado da natureza, através da observação direta da mesma, sem preconceitos a partir de onde chegou a uma visão de mundo. Tais concepções foram introduzidas na formação de Goethe e, provavelmente, foi a partir daí que nasceu seu espírito aventureiro que o levou a desenvolver grandes viagens. Em busca do conhecimento viajou pela Alemanha, à Suíça e, por duas vezes, à Itália. O conhecimento adquirido durante muitos anos de estudos científicos na área de ciências naturais concluiu as obras "Teoria das Cores", "Afinidade Eletivas", e "Viagem a Itália".

Sua produção Cientifica envolvia os campos mais diversificados do conhecimento, visto como um dos maiores mestres da literatura. Cientista, escritor, filósofo e o maior poeta, era um gênio universal que não parava de crescer; possuía um espírito holístico capaz de, com inteiro sucesso, abranger diversas áreas do conhecimento. Consagrou-se como um dos maiores poetas e dramaturgos de todos os tempos, munido também de um espírito universal capaz de abarcar todos os domínios da atividade humana. Sua obra literária fundamenta-se na representação da vida moderna, indicando opções para a superação artística das formas fragmentárias revivificadas da vida contemporânea.

Para muitos autores, é difícil separar ciência, poesia e literatura nas obras de Goethe, pois que, para ele, o conhecimento é utilitário num sentido muito forte, abrangendo o autoconhecimento individual, o conhecimento do mundo natural e a arte em sentido amplo. Hoje, Goethe é mais conhecido como um grande escritor do que pelas suas descobertas científicas, assim como Leonardo da Vinci, que se tornou mais conhecido pelo quadro da "Mona Lisa" do que por suas observações 
sobre hidráulica e geologia. Contudo, atualmente, o que raramente se diz é que Goethe foi também cientista, realizou pesquisas em campos tão variados como a óptica, a geologia, a mineralogia, a botânica e a zoologia.

De antemão, Goethe ficou conhecido por suas obras literárias, mas não se entregava à sua inspiração poética, e logo começou a se mostrar como um cientista. De início, não foi bem-vindo, pois o seu público e os cientistas o viam como um literato e não como um cientista. Ele próprio chegou a dar mais importância às suas investigações da natureza do que à criação literária.

Na sua maturidade, assimilou o romantismo, integrando-o, de um lado, a um classismo que representa um método de aproximar o homem com a natureza de forma indissoluvelmente unida, e, de outro, a uma concepção do mundo expressa na fusão da intuição com o pensamento.

Em sua vida longa, de intensas atividades científicas, Goethe estudou e produziu um conjunto de princípios, métodos e resultados de diversas pesquisas isoladas em diversas áreas do conhecimento não as tendo, contudo, sistematizado. Somente um século depois de sua morte, a sistematização de suas pesquisas veio ocorrer com o filósofo austríaco Steiner (1861-1925).

Suas pesquisas na área das ciências naturais aumentavam o gosto pelas viagens, realizou pesquisas por toda Alemanha, foi a suíça e duas vezes à Itália. O conhecimento adquirido durante muitos anos de estudos científicos, concluiu a obra "Teoria das Cores", escreveu o romance "Afinidades Eletivas" e "Viagem a Itália". Goethe escreveu da Itália a um amigo:

Depois do que vi, em matéria de plantas e peixes, em Nápoles e na Sicília, eu estaria tentado a fazer, se tivesse dez anos menos, uma viagem à Índia - não para descobrir coisas novas, mas para observar, a meu modo, as coisas já descobertas1.

Todas as constatações feitas por Goethe indicam o seu grau de interesse pelos estudos sistemáticos da natureza, embora não apareçam com suficiente destaque capaz de conferi-lhe autonomia quanto à condição de ser admitido também como um cientista. Contudo, ao promover tais relações com outros campos do conhecimento, promove um exercício que trará reflexos na condução de sua obra científica.

Mais significativa, ainda, do que essas realizações isoladas, a qual ele próprio chegou a dar mais importância, foi sua visão da natureza, em que sempre propalava a unidade do espírito humano mediante toda a sua história, permeando construções oriundas de tais campos, criando uma forma, se não nova em seus pontos, diferente de qualquer outra pelo grau de composição da representação.

Segundo Steiner (1985:25), "Goethe alcançou um método em acordo com a natureza e procurou introduzi-lo na ciência servindo-se de recursos disponíveis".
Seu pensar desenvolvido, o tornou o homem capaz de conhecer cada vez mais profundamente o mundo material, abrangendo os fenômenos físicos, químicos e alguns aspectos biológicos, procurando, pela análise, reconhecer, nas partes, o todo. Contudo, atualmente o que raramente se diz é que Goethe foi também cientista, realizou pesquisas em campos tão variados como a óptica, a geologia, a mineralogia, a botânica e a zoologia.

\section{O modo de se fazer ciência: Goethe, Mar- tius, Darwin e Humboldt}

Estes dados da biografia de Goethe ilustram a amplitude de seu interesse em vários campos de conhecimento, como também correspondia com os mais influentes cientistas de seu tempo. Mais que sua formação, é importante contextualizar a atenção de Goethe para com os elementos da natureza e suas concepções sobre o modo de se fazer ciência, privilegiando o trabalho de campo, pois representam igualmente a importância para alguns viajantes naturalistas tais como o botânico Karl Friedrich Phillipp Von Martius (1794-1868), Darwin e Humboldt.

É importante salientar, ainda, que as mudanças ocorridas na História Natural da Ciência nos séculos XVIII e XIX refletem um período tido como o momento de maior especialização e profissionalização entre os praticantes da História Natural. É claramente perceptível à busca da expansão do saber, por diversos autores na História da Ciência, a partir de seu papel, seja como botânico ou naturalista-viajante, cuja atenção era cada vez mais voltada para os funcionamentos internos e os sistemas fisiológicos.

Entre as distinções que se podem fazer entre os homens do saber da História Natural, especificamente a do viajante-naturalista e do naturalista de gabinete, uma citação por nós tomada de Dorinda Outram de Cuvier2, comenta as diferenças do trabalho de um naturalista de campo e dos naturalistas sedentários, de gabinete:

O naturalista de campo perpassa, com mais ou menos vagar por um grande número de áreas distintas, e é surpreendido sucessivamente por um grande número de objetos e de formas vivas interessantes. Ele os observa em seu meio natural, em relação com o seu ambiente em pleno vigor de sua vida e atividade. Mas ele só pode dedicar um instante de atenção a cada uma dessas formas e objetos. O naturalista sedentário é verdade, só conhece os seres vivos de terras distantes através dos relatos, sujeitos a erros em amor ou menor grau, com amostras sujeitas a danificações maiores ou menores. Ele não pode ver o grande cenário da natureza.

\section{Não obstante}

Se o naturalista sedentário não vê a natureza em ação, ele pode, entretanto pesquisar todos os seus produtos expostos à sua frente. Pode comparar os dados uns com os outros, 
tantas vezes quanto for necessário para obter conclusões confiáveis. Ele escolhe e define seus próprios problemas; ele pode examiná-los em seu lazer. Ele ainda pode trazer os fatos relevantes de qualquer lugar que sinta necessidade.

Enquanto isso, o viajante pode seguir apenas uma única rota; é somente no gabinete que se pode vagar verdadeiramente pelo universo, e para isso, é requisitado um tipo de coragem diferente, coragem que vem de uma limitada devoção para com a verdade, coragem que não permite que seu possessor deixe o objeto até que, através da observação, e através de um vasto conhecimento e pensamento coerente, ele o tenha iluminado com cada raio de luz a seu alcance, em um dado estado do "conhecimento"

Esta formulação de Cuvier possibilita-nos ressaltar a dimensão do trabalho de campo presente na exposição do conteúdo científico em Goethe, bem como dos viajantes naturalistas, ao expressar a importância da imersão absoluta nos elementos da natureza com o modo de investigação a favor da pesquisa em campo, em vez da pesquisa em gabinete.

Se o trabalho de gabinete exerce o distanciamento como um modo de investigação, enquanto o trabalho de campo necessita da imersão absoluta nos elementos da natureza, é necessária a observação do todo, ou, pela perspectiva de Goethe, intuir a natureza.

Goethe conferia em seus estudos morfológicos, prioridade ao conhecimento dos elementos da natureza enquanto vivos, criticando os métodos da História Natural, baseados no conhecimento dos seres vivos através da dissecação, como eram feitos a maior parte dos estudos de gabinete. A totalidade da natureza não pode ser encontrada através da dissecação das partes. Seu olhar voltava-se para a transformação, recusando a fixação estática dos seres vivos para o conhecimento destes.

Goethe procura proporcionar à natureza a oportunidade de revelar e, por assim dizer, expressar suas próprias leis sob circunstâncias que ele mesmo promove, assim não aceitava a substituição da observação pessoal pelo estudo em gabinetes ou uso de instrumentos, os quais poderiam acumular informações, mas não conduz a uma compreensão do fenômeno da forma de interagir com ele.

$\mathrm{O}$ viajante mais conhecido para a experiência de viagem é o naturalista Alexandre Von Humboldt. O mesmo realizou grandes expedições científicas, foi o primeiro a iniciar o trabalho de campo, era um observador rigoroso e detalhista nas suas anotações. Sua expedição pela América tornara-se modelo de trabalho científico para várias gerações de pesquisadores de campo. A esse respeito, Gottmann comenta, no início do século XIX: "os grandes geógrafos desta a época são os viajantes curiosos e sábios que acumulam observações sobre os países que visitam (...)".

Humboldt contribuiu muito para fazer com que os cientistas concentrassem sua atenção na necessidade de uma coleta precisa e sistemática de dados, e criou técnicas fundamentais de apresentação de dados tais como as isoternas e os perfis geológicos. Foi um protetor incondicional do talento científico, e um dos primeiros defensores da colaboração científica internacional.

Ao compartilhar a leitura de Helferich (2005), comenta que Humboldt, ao referir-se à descrição e a observação inspirada da natureza em um rigor científico, aponta ser necessário correr o risco nas viagens para se fazer as observações necessárias. Para ele, o cientista precisa virar explorador, e somente desta forma, a ciência pode assumir seu verdadeiro papel e deixar de ser um dogma.

Seguindo este caminho, percebemos que a explicação que Humboldt oferece ao leitor, acerca desse despertar estético para a natureza, o surgimento de um desejo de investigação do conhecimento, de suas leis e situações, e da representação de suas forças e grandiosidades, as mais exatas possíveis. Para ele, as impressões estéticas experimentadas pelo viajante em cada região fazem parte da própria atividade científica e não podem ser substituídas por descrições ou amostras destacadas dos lugares de onde foram coletadas. Neste sentido, coaduna-se com o pensamento de seu amigo Goethe, ao expressar:

Enquanto na ciência o pesquisador mergulha nas profundezas da realidade para lhe vazar as forças atuantes em conceitos, o artista procura incorporar estas mesmas forças atuantes ao seu material (HELFERICH, 2005, p.202).

Com Martius, a relação de Goethe pautava-se na necessidade de compreender, em primeiro plano, as plantas em seu contexto de origem, em relação com outras plantas e o solo, com os seres vivos dos quais elas são cercadas. Martius valorizava a apreciação das plantas in loco, pelo conhecimento dos objetos em vida, em contraste com o estudo por dissecação, a partir de materiais mortos, como era feito maior parte dos estudos de gabinete. Assim, criticava os métodos da História Natural, afastando-se da ciência realizada em gabinete, e inclinando-se sobre as espécies, a partir da análise das funções de seus órgãos.

Martius veio ao Brasil liderando uma expedição científica do Rio de Janeiro à Amazônia, de 1817 a 1820. Um dos resultados desta expedição foi à publicação dos três volumes da obra Viagem pelo Brasil em 1823,1828 e 1831. Com as narrativas de Martius sobre as localidades Brasileiras, Goethe ficou conhecendo um pouco o Brasil, onde forneceu algumas amostras do material recolhido durante a expedição (SOUSA, 2000)3.

Goethe foi precursor de Darwin, tendo falecido 27 anos antes de Darwin proclamar seu princípio holístico da evolução orgânica. Foi declarado companheiro de Darwin pelo biólogo Ernst Haeckel, ao lado de Jean Lamarck, pois, diante da origem de todos os grandes filósofos da natureza, foi o primeiro a estabelecer uma 
teoria do desenvolvimento orgânico. Foi, então, homenageado, ao emprestar o nome "Goethea" a um gênero da planta, pela sua contribuição para um conhecimento maior dos "Seus Verdes da Natureza". Posteriormente, a aparição de Darwin no cenário científico propiciou o reconhecimento das formulações de Goethe a respeito da metamorfose das plantas.

Goethe contribuiu com os estudos de Darwin. Os princípios que os diferenciavam eram que este último presumiria que influências externas (causas mecânicas) agem sobre a natureza de um organismo o modificariam, enquanto Goethe deduzia que "as alternativas ímpares eram várias expressões de um organismo arquetípico (urorganismos) que possuiria em si a capacidade de assumir formas multifárias e que em determinado momento assumiria aquela que melhor se adequasse ás condições de seu meio ambiente". Suas idéias foram anunciadas em seu primeiro ensaio, "A Metamorfose das Plantas", em cuja publicação seu editor interferiu, alegando ser um literato e não um cientista. Esta visão errônea de não conceber na mesma mente humana de Goethe a criatividade poética e a pesquisa científica, por seus contemporâneos, ocasionava-lhe grande sofrimento.

Outra contribuição sua dada à ciência concerne ao crescimento da vegetação de dois modos distintos - vertical e espiraladamente - uma década antes de Darwin abordar o mesmo assunto.

Segundo Steiner (1984):

Foram das observações similares as de Goethe que Darwin partiu para afirmar sua dúvida sobre a constância das formas externas dos gêneros e espécies. Enquanto Darwin considerou que toda a natureza do organismo se encontrava de fato compreendida nessas características, concluindo, por conseguinte, que nada há de constante na vida das plantas, Goethe foi mais longe e inferiu que, sendo inconstante as características, o que há de constante deve ser perseguido em algo que repousa por trás das extremidades mutáveis (p.54).

É importante assinalar, neste contexto, a amizade e a contribuição de Goethe para com os estudos de Humboldt uma influência mais significativa em sua formação intelectual.

\section{O método fenomenológico de Goethe}

A fenomenologia de Goethe apresentada a seguir corresponde a uma metodologia científica resgatada por Steiner, a qual aborda a visão de mundo implícita nos escritos goetheanos.

A prática do método científico de Goethe representa um exercício e um desafio para os cientistas, conforme eles testam e desenvolvem a sua habilidade para "ver" a unidade da natureza e a multiplicidade de suas partes. É de fundamental importância a atenção no estudo do fenômeno, como também uma consciência aberta, boa vontade e disposição para apreciar e perceber a ocorrência do mesmo. Para tal, é necessário o uso do "sutil empirismo", que Goethe procura acordar nos cientistas; isto associado à segurança e à auto confiança, os quais são fatores de fundamental importância para o cientista, como também o são, o interesse e a atenção prestada ao fenômeno sob estudo.

O temor da subjetividade dissolve-se no esforço consistente e em uma metodologia rigorosa e autocrítica do cientista. Na experimentação, questiona-se o próprio fenômeno, que apresenta uma estrutura conceitual racional. O completo entendimento do fenômeno pode levar sua estrutura racional à autoconsciência, e isto deve ser o objetivo da ciência fenomenológica, constituindo, assim, um método com "um ponto de equilíbrio entre a contemplação imparcial do fenômeno e a implementação e controle das condições experimentais".

Steiner, ao falar do caminho cognitivo, cita as precondições para se estudar qualquer coisa no plano da realidade, seja externa ou interna (isso serve para a vida inteira e não só para o estudo da Antroposofia). A primeira é a capacidade de ADMIRAÇÃO (veneração), interesse pelo fenômeno escolhido para a observação (é o que a criança tem muito forte). Quando o intelecto vem, inicia-se a critica e fecha-se esta porta. A segunda coisa necessária é NÃO TER PRECONCEITOS. Você tem que ter uma mente aberta; evitar analisar ou criticar, mas apenas observar e relatar. Procurar olhar as coisas e, só depois, com o tempo, ver se é verdade ou mentira. A terceira condição é a CALMA INTERIOR, sem ansiedade - devemos estar tranqüilo para nos dedicarmos ao fenômeno observado, em estado de silêncio que permite que o mundo exterior seja executado no seu interior.

Neste momento, iremos utilizar a descrição sumária detalhada do método fenomenológico de Goethe, usado por Ghelman (2000) na divulgação desta metodologia. Este método fenomenológico de Goethe, resgatado por Rudof Steiner, envolve quatro passos que obedecem a um caminho de aprofundamento qualitativo para os fenômenos vivos (plantas, animais, paisagens), que podem ser desenvolvidos metodicamente.

\section{Passo I - Percepção sensorial exata do fenômeno}

Deve-se olhar para o fenômeno, observá-lo e fazer uma descrição escrita exatamente do que se vê naquele instante, sem se importar com o passado. Anotar minuciosamente, todas as características possíveis como a cor, o cheiro, a textura etc., de modo que, ao fechar os olhos, você consiga desenhar tudo num mapa. Devem-se fazer listas, fotografias, mapas, desenhos, enfim tudo o que puder ficar registrado como documentação do lugar, são ferramentas essenciais para realizarmos uma observação precisa, pois quando paramos para desenhar, nos aproximamos mais dos detalhes e da essência do observado. 


\section{Passo II - Percepção temporal do fenômeno}

Deve-se evidenciar a relação entre as diversas partes, percebendo os espaços entre elas, e a transformação de uma parte do fenômeno em outra através do tempo. Para tal, faz-se necessário imergir no primeiro passo - a descrição dos fatos - e mover-se na observação.

Neste não se observa mais o espaço, e sim o intervalo entre as manifestações no tempo. Não se olha agora cada parte, mas olha-se o que se está transformando ao longo do processo visível, ou seja, deve-se caminhar livremente ao longo do fenômeno. Neste passo, devese perceber o invisível, ou seja, o TEMPO através da metamorfose, enquanto que no primeiro você ainda percebe sensorialmente o ESPAÇO. A história do lugar será estudada por meio dos materiais registrados como documentação no primeiro passo.

É importante evidenciarmos o ciclo de conscientização que vai sendo desenvolvido. "( ao invés de," depois de "desenvolvido") Goethe, explica: Cada ato de olhar se torna uma observação, cada ato de observação uma reflexão, cada ato da reflexão produz associações; assim, fica evidente que teorizamos cada vez que olhamos o mundo cuidadosamente.

\section{Passo III - Contemplação}

O que se deve fazer: percepção do gesto anímico do fenômeno. O gesto anímico é o gesto que emana do fenômeno e que penetra na alma, é o sentimento exato que surge na percepção que se tem do fenômeno. Deve-se olhar e desenvolver sozinho a percepção do fenômeno.

\section{Passo IV - Intuição}

Você e o fenômeno são uma coisa só. Este passo liga a vontade com o pensamento, manifestando a chama "intuição terapêutica ou pedagógica". Para desenvolver este passo, o conhecimento vivo fenomênico se faz necessário para que as relações se estabeleçam naturalmente.

Assim, o modo de pensar realiza sua meta, ou seja, integra dois mundos ou duas naturezas do mesmo mundo; a natureza sensorial, que nos chega de fora, e a natureza, que nos chega de dentro, a partir do mundo das ideias, ambas difundidas no fenômeno (phen = manifestação; nomen = nome, essência).

\section{Influências das idéias de Goethe a de Humboldt}

Goethe teve grande importância na formação intelectual do naturalista Alexandre Von Humboldt (1769-1859), na realização do pensamento do poeta sobre ciência. Segundo o próprio Humboldt, em uma carta de 14 de maio de 1806 a Karoline Von Wozogen, a influência que Goethe manteve em sua vida "o sentimento da grande influência da sociedade de Jena persegue-me por todas as partes, já que as idéias de Goethe a respeito da natureza e, por assim dizer, dotaram-me de novos órgãos" (HUMBOLDT, 1980 d: 162).

Num posfácio a uma edição alemã do Ansichten der Natur, Adolf Meyer-Abich4, reafirma a importância que o encontro com Goethe teve para a formação intelectual de Humboldt: "Humboldt pode ser pensado como o completador das pesquisas de Goethe sobre a Natureza" comenta o autor.

Uma das primeiras questões, talvez a mais importante, que poderíamos aproximar Goethe de Humboldt, diz respeito à pratica do trabalho de campo, comentada anteriormente. Humboldt foi o primeiro na Geografia a realizar um trabalho de campo sistemático, valorizava a observação minuciosa dos elementos da paisagem, no sentido de fazer a ligação do particular com o que pode ser encontrado de mais geral (ALVES, 2005)

O objetivo de Humboldt refere-se à exposição do princípio da unidade e totalidade da natureza, da compreensão do mundo, dos fenômenos e das formas físicas em sua conexão e mutua influência, ou seja, para Humboldt, é possível sintetizar homem e natureza, natureza orgânica e inorgânica, e todas as conexões da natureza. Semelhantemente, o que se pode comentar a respeito da ideia de Goethe, possuía uma visão holística, não analisava apenas um fato isolado, e sim as relações de causa e conseqüências entre eles.

Nas suas palavras Goethe5:

\begin{abstract}
A teoria em si e por si nada serve se não nos fazer crer na conexão dos fenômenos, pela ciência estamos constantemente juntando e relacionando fatos que, na experiência, são separados. Na natureza inorgânica, vemos separados as causas e os efeitos e procuramos sua conexão nas ciências correspondentes. No mundo orgânico, percebemos gêneros e espécies de organismos e empenhamo-nos em investigar suas inter-relações. Na história, deparamo-nos com épocas culturais isoladas e empenhamo-nos em conhecer a dependência intrínseca entre uma e outra etapa evolutiva (STEINER, 2004, p.30).
\end{abstract}

Complementa ainda a identificação com as visões holísticas de Goethe, fornecendo uma explicação para o valor artístico que Humboldt desejava imprimir à sua obra, pois, para o poeta alemão, o verdadeiro conhecimento dependia de uma íntima colaboração entre arte e ciência.

Conforme relata Goethe6,

Para encontrar-te no infinito, deves diferenciar e então juntar, no sentido que a diferenciação caberia ao cientista e a síntese ao artista. A ciência, baseada em um método analítico, permitiria o reconhecimento das diferenças, mas somente a arte seria capaz de efetuar a síntese desses elementos dispersos e apresentá-los em um olhar essencial7. 
Humboldt não via a incompatibilidade entre o método experimental e a visão sublime da natureza. Para ele, a análise científica também produzia uma grande satisfação estética. Influenciado por Schelling e pelos pintores de paisagem que acompanhavam as expedições, interessou-se pela vegetação como sublime representação do transcendental. Pode-se dizer que Humboldt foi o cientista da Filosofia-da-natureza, pois combinou a atividade científica com a grandeza romântica, em que sua obra Cosmo pode ser considerada a ciência universal do movimento romântico (HELFERICH, 2005).

Novamente compartilhando a leitura de Helferich (2005), o mesmo comenta que Humboldt, ao referir-se à descrição e observação inspirada da natureza em um rigor cientifico, indagava: "o que seria conhecimento científico sem apreciação estética? De que adiantava a pessoa saber que a atmosfera da Terra era $78 \%$ nitrogênio, se não conseguisse se comover com a beleza do céu límpido de verão?" (p. 58).

Seguindo este caminho, percebemos que a explicação que Humboldt oferece ao leitor, acerca desse despertar estético para a natureza, o surgimento de um desejo de investigação do conhecimento, de suas leis e situações, e da representação de suas forças e grandiosidades, as mais exatas possíveis. Para ele, as impressões estéticas experimentadas pelo viajante em cada região fazem parte da própria atividade científica e não podem ser substituídas por descrições ou amostras destacadas dos lugares de onde foram coletadas. Neste sentido, coadunase com o pensamento de seu amigo Goethe, ao expressar "Enquanto na ciência o pesquisador mergulha nas profundezas da realidade para lhe vazar as forças atuantes em conceitos, o artista procura incorporar estas mesmas forças atuantes ao seu material" (STEINER, 1984, p.33).

Assim, Humboldt herda e acolhe o elemento essencial no exercício da observação, o fato de que a contemplação da paisagem não poderia ocorrer de maneira fria, sem emoção. A natureza deve ser observada com os sentimentos, o observador deve deixar fluir toda a sua sensibilidade.

Expressa:

A natureza é o reino da liberdade, e para pintar vivamente as concepções e os prazeres que engendra seria preciso dar ao pensamento uma expressão livre e nobre em harmonia coma grandeza e majestade da criação.

\section{Continua:}

Se se considerar o estudo dos fenômenos físicos, não em sua relações com as necessidades materiais da vida, senão em sua influência geral sobre os progressos intelectuais da humanidade, é o mais elevado e importante resultado desta investigação, o conhecimento da conexão que existe entre as forças da natureza e o sentimento íntimo de sua mútua dependência. A intuição destas é a que engrandece os pontos de vista e enobrece nossos prazeres. Esse alargamento de horizontes é a obra da observação, da meditação e do espírito do tempo no qual se concentram as direções todas do pensamento.(op.cit.:40).

Nesta passagem, Humboldt apresenta um outro elemento importante no processo de observação dos fenômenos, aquele também encontrado nas discussões de Goethe ao abordar a valorização da estética, enquanto campo filosófico que trabalha com a intuição fazendo a mediação entre o sujeito-objeto. Para Humboldt (1848a: 76), “a ciência é o espírito aplicado a natureza, mas o mundo exterior só passa a existir para nós no momento em que, pela via da intuição se reflete no nosso interior".

\section{Considerações finais}

É certo que o método de trabalho de Goethe vinha ao encontro das convicções de Humboldt, parecendo ser a realização prática do seu sonho. Tal situação fica transparente principalmente quando Humboldt considera a observação como ponto de partida para a investigação da paisagem, como também, ao considerar a contemplação, a intuição, a unicidade, e a lei da analogia. Há evidencias nos estudos de Humboldt de que ele foi influenciado por certas concepções de Goethe, como também de sua postura metodológica e no nível filosófico.

Enquanto Goethe designou um método em acordo com a natureza, Humboldt parte dos conceitos gerais dos fatos concretos, comparando-o, e, trabalhando desta forma, o fundamento conceitual aparece. Seu método é baseado na experiência pura. Em Humboldt encontramos em seu objetivo, referindo-se a exposição do princípio da unidade e totalidade da natureza, da compreensão do mundo, dos fenômenos e das formas físicas em sua conexão e mutua influência.

\section{Notas}

${ }^{1}$ Extraído do Livro "A metamorfose das plantas" prefácio de edição Kollert, p.5

${ }^{2}$ Apud Dorinda Outram,op.cit., pp.259-261

${ }^{3}$ Sousa, Celeste O Brasil na Obra de Goethe. Fórum Deutsch-revista brasileira de estudos Ribeiro de germânicos. Rio de janeiro, v.4, n.1, p.26-44. 2000

${ }^{4}$ Adolf Meyer-Abich, "Nachwort", in: Humboldt, Ansicheten der Natur, op.cit., p.149

${ }^{5}$ Goethes Naurwissenschaftliche Schriften (cit), vol. V: Sprüche in Prosa, p. 357.

${ }^{6}$ Escreveu Goethe em uma passagem de um poema dedicado ao pesquisador de nuvens Luke Howard, em 1803, encontra-se no livro - Dich im Unedlichen finden,/ Musst unterscheiden und dann verbinden" Cf. Goethe Goethe Werke, Há, München: beck, 1989, vol. 1p. 349.

${ }^{7}$ Sobre as relações entre arte e ciência em Goethe, ver os artigos de Werner Busch, "Die Ordnung im Flüchtigen - Wolken studie der Goethezeit" e "Der bergals Gegentand Von Naturwissenschaft und kunst. Zur Goethes Geologischem begriff, in: Sabine Schulze (org.) Goethe und die kunst, Frankfurt e Weimar, 1994., pp.485-570. 


\section{Referências}

ALVES, V.E.L. A Obra de Humboldt e sua provável influência sobre a antropologia de Franz Boas. GEOUSPEsapaço e tempo, são Paulo, no 18,2005.

STEINER, R. A Obra Científica de Goethe. trad. Rudolf Lanz, São Paulo: Antropósofica, 1984a, 204p.

1985b,53p.

Verdade e Ciência. São Paulo: Antroposófica,

O Método Cognitivo de Goethe: Linhas Básicas para uma Gnosiologia da Cosmovisão Goethiana. Trad. Bruno Callegaro e Jacira Cardoso. $2^{\circ}$ ed. Atual. São Paulo: Antroposófica, 2004,

GOETHE, J. W. Schriften zur botnik um wissenschaftsleher. Munchen: Deutscher Taschenbuch Verlag, 1963.

GHELMAN R. Fenomenologia de Goethe. In: Agricultura Biodinâmica: A Dissociação entre Homem e Natureza. Anais da IV Conferência Brasileira de Agricultura Biodinâmica. Ed. Antroposófica. 260-271, São Paulo, 2000

HELFERICH, GERARD. O Cosmo de Humboldt: Alexandre Von Humboldt e a viagem à América Latina que mudou a forma como vemos o mundo. Tradução de Adalgisa Campos da Silva. Rio de Janeiro: Objetiva, 2005390 p.

HUMBOLDT, A. Von. Cosmos, vols. I (a),II(b), III(c),Iv(d). Paris, Gide et J. Baudry, 1848.

HUMBOLDT, A. Von. Cartas Americanas. Caracas, Biblioteca Ajacucho, 1980.

VEIGA GREUEL. Arte e Estética segundo Goethe: Goethe como Inaugurador de uma Estética Nova. Tradução de Marcelo da Veiga Greuel. - 2.ed. São Paulo: Antroposófica, 1998, 38p. 